\title{
Biochemical and hematological changes among anemic and non-anemic pregnant women attending antenatal clinic at the Bolgatanga regional hospital, Ghana
}

\author{
Benjamin Ahenkorah ${ }^{1,4,5^{*}}$ (D) Kwabena Nsiah ${ }^{2}$, Peter Baffoe ${ }^{3}$ and Enoch Odame Anto ${ }^{5,6,7}$
}

\begin{abstract}
Background: Anemia in pregnancy may not only be associated with maternal morbidity and mortality but can also be detrimental to the fetus. A definitive diagnosis of anemia is a pre-requisite to unravelling possible cause(s), to allow appropriate treatment intervention. It is hypothesised that measured hemoglobin (HGB), complemented by biochemical and other hematological parameters would enhance anemia diagnosis.

Methods: This was a cross-sectional study among 400 pregnant women comprising 253 anemic and 147 nonanemic pregnant women, attending an antenatal clinic at Bolgatanga Regional Hospital, Ghana. Venous blood was collected and hemoglobin genotype, complete blood count and biochemical parameters [ferritin, iron, total iron binding capacity (TIBC), transferrin saturation (TfS), C-reactive protein (CRP) and bilirubin] were determined. Thick blood films were prepared for malaria parasitemia, while early morning stool and midstream urine samples were examined for enteric and urogenital parasites, respectively.
\end{abstract}

Results: There were significantly reduced levels of HGB $(p<0.0001)$, HCT $(p<0.0001)$, MCV $(p<0.0001)$, iron (0.0273), ferritin ( $p=0.018)$ and transferrin saturation (0.0391) and increased WBC $(p=0.006)$, RDW $(p=0.0480)$, TIBC $(p=0.0438)$ and positivity of CRP in anemic, compared to non-anemic pregnant women. Anemic women were associated with increased proportion of hemoglobinopathies (AS, SS and SC), Plasmodium falciparum, Schistosoma hematobium and intestinal parasite infections.

Conclusion: Anemic pregnant women are associated with a significant derangement in hematological and iron indices that implicate iron deficiency. This was influenced by hemoglobinopathies and parasitic infections.

Keywords: Anemia, Pregnant women, Hematological, Biochemical, Iron deficiency

\section{Background}

Anemia is the most prevalent nutritional deficiency problem during pregnancy. Iron deficiency anemia is the leading cause of anemia in most developing countries [1]. Anemia and iron deficiency anemia are often used interchangeably and the prevalence of anemia taken to be the same as that of iron deficiency [1]. It has been reported that $56 \%$ of pregnant women in low

\footnotetext{
*Correspondence: benahenkorah.cos@gmail.com; bennahie@yahoo.com ${ }^{1}$ Biochemistry and Hematology Units, Bolgatanga Regional Hospital, P.O. Box 26, Bolgatanga-Upper East Region, Ghana

${ }^{4}$ Department of Biochemistry and Molecular Medicine, School of Medical and Health Science, University for Development Studies, Tamale, Ghana Full list of author information is available at the end of the article
}

income countries are affected [2], in contrast to $18 \%$ in high income countries [3].

In Ghana, anemia has been attributed to poor bioavailability of iron in the diet, which is due to the low intake of foods that enhance absorption of iron [4-6]. During pregnancy, there is disproportionate increase in the plasma volume, relative erythrocyte number, leading to a fall in hemoglobin concentration [7]. Moreover, the iron requirement generally exceeds the amount provided in the diet [8]. Intestinal iron absorption increases during pregnancy but becomes poor in cases of associated parasitic infectious diseases, such as hookworm and roundworm infestations [9].

(c) The Author(s). 2018 Open Access This article is distributed under the terms of the Creative Commons Attribution 4.0 International License (http://creativecommons.org/licenses/by/4.0/), which permits unrestricted use, distribution, and 
Anemia during pregnancy is associated with a number of maternal and fetal disorders including the risks of preterm births, low birth weight babies, perinatal mortality and intrauterine growth retardation [10,11]. Formation of fetal hemoglobin and myoglobin requires iron. Fetal iron is obtained from maternal stores, which progressively leads to depletion of iron in the mother. Therefore, adequate iron is required for a successful pregnancy and fetal outcomes [12].

A number of hematological [13, 14] and iron-related indices [15] have been used in the diagnosis of anemia in pregnancy. Although serum ferritin concentration of less than $12 \mu \mathrm{g} / \mathrm{L}$ is usually used as an indicator of iron deficiency [16], in tropical countries, a cut-off of $30 \mu \mathrm{g} /$ $\mathrm{L}$ has been recommended as being the best indicator of deficient iron stores [17]. Elevated ferritin level, serum transferrin, transferrin receptor (TfR), TIBC, erythrocyte sedimentation rate, and $\mathrm{C}$-reactive protein concentrations, and reduced serum iron concentrations and transferrin saturation are usually associated with anemia of chronic disease [18].

The routine assessment of anemia has been based on hemoglobin levels of $<11 \mathrm{~g} / \mathrm{dl}$. However, other red cell indices such as $\mathrm{MCV}, \mathrm{MCH}, \mathrm{MCHC}$ and RDW have been widely employed in anemia diagnosis [18]. A reduced $\mathrm{Hb}$, MCV below the lower reference limit for normal and an increased RDW above the upper reference limit for normal have been associated with microcytic anemia in pregnancy [19].

Although the anemic condition is progressive throughout pregnancy and is known to alter the red cell indices and iron status, few studies have studied both factors in pregnancy. Some studies, apart from measuring these factors independently, did not simultaneously consider the effect of Plasmodium parasite, intestinal parasites and Schistosoma hematobium infestation. It is against this background that we determined the changes in iron status and red cell indices, along with the presence of sickle cell and parasitic infections, among anemic and non-anemic pregnant women, visiting an antenatal clinic at the Bolgatanga Regional Hospital, Ghana.

\section{Methods}

\section{Study design and setting}

This hospital-based cross-sectional case-control study was conducted in the Obstetrics and Gynecology Department of the Regional Hospital Bolgatanga (RHB), Ghana, West Africa from May, 2013 to May, 2014.

\section{Study population and participant recruitment}

A total of 400 pregnant women, comprising 253 anemic pregnant women with hemoglobin concentration $<11 \mathrm{~g} / \mathrm{dl}$ using WHO criteria [20], were considered as cases and
147 non-anemic pregnant women of hemoglobin concentration $>11 \mathrm{~g} / \mathrm{dl}$, were purposively recruited as control.

\section{Inclusion and exclusion criteria}

The study included all pregnant women attending their first antenatal care, of ages ranging from 15 to 48 years. Pregnant women in need of emergency care or having an at-risk pregnancy such as gestational diabetes, pre-eclampsia and eclampsia, were excluded. Antenatal pregnant women reporting for repeat visits during the study period and subjects who had been confirmed to be HIV positive were also excluded from the study.

\section{Specimen collection and processing}

Five (5) milliliters (mls) of participants' venous blood samples were drawn for hematological and biochemical analysis, between the hours of 8:00 am and 9:00 am. About $2 \mathrm{mls}$ were collected into BD vacutainers, containing EDTA for determination of hematological parameters and 3mls into BD Vacutainers with SST II Advance semi-separator gel, for determination of biochemical parameters. Samples in SST were centrifuged at $3000 \mathrm{rpm}$ for $10 \mathrm{~min}$ and serum samples were aliquoted into cryotubes and stored at $-80^{\circ} \mathrm{C}$ until assay. Also, about 2 drops $(6 \mu \mathrm{l})$ of blood were collected on a slide for the preparation of thick blood film to detect the presence of malaria parasites, according to the protocol described by Ahenkorah et al. [21].

About two grams (2 g) of early morning stool and 10 mls midstream early morning urine samples were also collected into sterile containers. The urine was used for the determination of Schistosoma hematobium ova/cyst and the stool for the determination of intestinal parasites. The collected samples were transferred in a cold box to the Biochemistry and Hematology Laboratory of $\mathrm{RHB}$, for the required investigations.

\section{Hematological assay}

Full blood count was performed using the Sysmex KX-21 N Automated Hematology Analyzer (Sysmex Corporation Kobe, Japan) Whole Blood Mode. The parameters for the full blood count determination were; WBC, HGB, HCT, RDW, MCHC and MCV. Routine quality control checks were run on control specimen within specified limits per the manufacturer's instructions. Hematology analyzer was calibrated per the instructions of the manufacturer when there was a change of reagent. The presence of $\mathrm{Hb}$ variants was detected on a hemolysate prepared from EDTA sample on cellulose acetate paper at $\mathrm{pH} 8.5$, using an electrophoresis set-up (Beijing Liuyi Instrument Factory, China). 


\section{Biochemical assay}

Serum ferritin was measured, using the AXSYM, MEIA quantitative technique. Serum iron and UIBC were assayed by the modified method of Henry (1984), using the BT3000 Plus Chemistry Analyser (Biotecnica Instruments, Rome, Italy). Transferrin saturation index was calculated by dividing serum iron by TIBC and expressing the result as a percentage. Bilirubin determination was based on the modification of Tietz's method (1994). Daily quality control checks were run on control specimen within specified limits per the manufacturer's instructions. Clinical chemistry analyzer was calibrated per the instructions of the manufacturer when there was a change of reagent.

The CRP Latex test was used to determine the level of inflammation. It is a rapid slide agglutination test for the qualitative and semi-quantitative detection of $\mathrm{C}$-reactive protein in serum. The reagent, containing particles coated with specific anti-human C-reactive protein antibodies, agglutinates in the presence of CRP in the patient's serum.

\section{Malaria parasite screening}

Parasitemia was determined using both the parasite density and plus (+) system. All the thick blood smears were stained with $10 \%$ Giemsa and examined under the $\times 100$ oil immersion objective lens of a light microscope. For parasite density determination, the number of asexual parasites was counted against 200 leucocytes, where an average leucocytes count of $8000 / \mu \mathrm{L}$ was assumed. The blood smear was considered negative when 200 high power fields had been examined without visible parasite [22].

For the plus $(+)$ system counting of parasite, the results were categorised as follows:

1-9 parasites per 100 microscopic fields $(+)$; 10-99 parasites per 100 microscopic fields $(++)$; $1-9$ parasites per microscopic field $(+++)$; more than 10 parasites per microscopic field $(++++)$. The examination of the blood film for malaria parasites was done by two certified microscopists independently who were blinded to each other's results [23].

\section{Stool and urine analysis}

The formol-ether concentration method was used in the preparation of stool samples for microscopy and detection of intestinal parasite.

The urine sedimentation technique was used to detect the presence of $S$. hematobium ova. About $10 \mathrm{mls}$ of urine was filtered using paper filters and the egg/ova count was recorded per $10 \mathrm{mls}$ of urine.

\section{Statistical analysis}

Data were entered into Microsoft Excel worksheet. Results were presented as mean \pm standard deviation (SD) and frequency (percentage) and geometric mean $(95 \% \mathrm{CI})$, where necessary. The Fischer's exact test or Chi-square $\left(\mathrm{X}^{2}\right)$ was used to assess the statistical significance of categorical variables. Unpaired sample t-test was used to compare between two means of continuous variables for normally distributed data and Mann-Whitney $U$ test was used to compare between two medians of continuous variable for non-parametric variables. $P$-value less than 0.05 was considered statistically significant. Analysis was performed using GraphPad Prism 5 Project software (GraphPad software, San Diego California USA, www.graphpad.com).

\section{Results}

Table 1 shows the biochemical profiles of study participants. There was no statistically significant difference between the mean ages of anemic pregnant women (27.53 \pm 5.31 years), compared to non-anemic pregnant women $(28.02 \pm 4.97$ years $)(p=0.309)$. Anemic pregnant women had a significantly lower mean HGB, HCT, MCV, MCHC than their non-anemic counterparts $(p<0.0001)$. Conversely, there was a significantly higher mean WBC and RDW amongst anemic pregnant women $(p<0.05)$. There were statistically significant increased levels of TIBC in anemic pregnant women, compared to the non-anemic pregnant women. The anemic pregnant women also had significantly lower median levels of serum ferritin $(p=0.0180)$, iron $(p=0.0273)$ and \%TfR saturation $(p=0.0391)$. Bilirubin (total, direct and indirect) levels were lower in the anemic than the non-anemic pregnant women $(p>0.05)$. A higher proportion of anemic pregnant women had $\mathrm{MCV}<80 \mathrm{fl}(16.9 \%$ vs $5.4 \%$; $p=0.0115)$, RDW $>15.0 \%(15.0 \%$ vs. $3.4 \% ; p=0.0052)$, serum iron $<40 \mu \mathrm{g} / \mathrm{dl}(18.6 \%$ vs. $6.1 \% ; p=0.0092)$, ferritin $<12 \mathrm{ng} / \mathrm{ml}(16.2 \%$ vs. $6.1 \% ; p=0.0400)$ and TIBC $>500 \mu \mathrm{g} / \mathrm{dl}(15.4 \%$ vs. $3.4 \% ; p=0.0015)$, compared to non-anemic pregnant women.

Table 2 shows the association between anemia and parasitemia. Higher proportion of women with anemia had malaria parasitemia, and intestinal parasitic infections. There was a statistically significant association between anemia and malarial parasitemia $(p=0.0111)$, as well as intestinal parasite $(p=0.0152)$. The proportion of $+1(20.6 \%$ vs. $9.5 \%)$ and $2++(4.0 \%$ vs. $0.7 \%)$ malaria parasite was significantly higher in anemic, compared to non-anemic. There was a significantly increased geometric mean of ring trophozoite of Plasmodium falciparum among anemic pregnant women $(2159 \mathrm{pa} / \mu \mathrm{l}$ blood $)$, compared to their non-anemic counterparts $(809.4 \mathrm{pa} /$ $\mu \mathrm{l}$ blood $)(p=0.0487)$. The proportion of intestinal parasite $1+$ among anemic women (27.7\%) was significantly higher, compared to non-anemic (18.4\%) counterparts $(p=0.0152)$. All schistosomiasis infections were found in anemic participants, giving a proportion 
Table 1 Hematological and biochemical profile stratified according to anemic and non-anemic pregnant women

\begin{tabular}{|c|c|c|c|}
\hline Parameters & Anemic & Non-anemic & $p$-value \\
\hline & $(n=253)$ & $(n=147)$ & \\
\hline Maternal age (years) & $27.53 \pm 5.31$ & $28.02 \pm 4.97$ & 0.309 \\
\hline \multicolumn{4}{|l|}{ Hematological profile } \\
\hline $\mathrm{HGB}(\mathrm{g} / \mathrm{dl})$ & $9.31 \pm 1.34$ & $11.89 \pm 0.80$ & $<0.0001$ \\
\hline WBC $(/ \mu \mathrm{L})$ & $10.26 \pm 1.68$ & $6.13 \pm 1.39$ & 0.0006 \\
\hline HCT (\%) & $29.08 \pm 3.34$ & $35.43 \pm 4.76$ & $<0.0001$ \\
\hline $\mathrm{MCHC}(\mathrm{g} / \mathrm{dl})$ & $31.88 \pm 2.02$ & $33.43 \pm 1.58$ & $<0.0001$ \\
\hline MCV (fl) & $78.72 \pm 9.02$ & $85.94 \pm 8.32$ & $<0.0001$ \\
\hline RDW (\%) & $16.87 \pm 5.95$ & $14.79 \pm 3.55$ & 0.048 \\
\hline \multicolumn{4}{|l|}{ Biochemical profile } \\
\hline Serum ferritin $(\mathrm{ng} / \mathrm{ml})^{\mathrm{a}}$ & $19.7(15.2-94.0)$ & $29.3(21.4-106)$ & 0.0180 \\
\hline Serum iron $(\mu \mathrm{g} / \mathrm{dl})^{\mathrm{a}}$ & $88.3(73.9-182)$ & $152.7(81.0-201)$ & 0.0273 \\
\hline $\operatorname{TIBC}(\mu \mathrm{g} / \mathrm{d} \mid)^{\mathrm{a}}$ & $369(118.0-532.0)$ & $302(93-379)$ & 0.0438 \\
\hline TfS $(\%)^{\mathrm{a}}$ & $20.7(6.6-26.4)$ & $24.6(8.1-27.5)$ & 0.0391 \\
\hline Total Bilirubin $(\mu \mathrm{mol} / \mathrm{l})$ & $18.09 \pm 6.63$ & $18.64 \pm 6.33$ & 0.564 \\
\hline Direct Bilirubin $(\mu \mathrm{mol} / \mathrm{l})$ & $5.45 \pm 2.13$ & $5.82 \pm 2.37$ & 0.249 \\
\hline Indirect Bilirubin $(\mu \mathrm{mol} / \mathrm{l})$ & $12.79 \pm 6.08$ & $13.26 \pm 6.06$ & 0.593 \\
\hline $\operatorname{MCV}(<80 \mathrm{fL})^{\mathrm{b}}$ & $43(16.9 \%)$ & $8(5.4 \%)$ & 0.0115 \\
\hline RDW $(>15 \%)^{b}$ & $38(15.0 \%)$ & $5(3.4 \%)$ & 0.0052 \\
\hline Serum iron $(<40 \mu \mathrm{g} / \mathrm{dl})^{\mathrm{b}}$ & $47(18.6 \%)$ & $9(6.1 \%)$ & 0.0092 \\
\hline Ferritin $(<12 \mathrm{ng} / \mathrm{ml})^{\mathrm{b}}$ & $41(16.2 \%)$ & $9(6.1 \%)$ & 0.0400 \\
\hline $\operatorname{TIBC}(>500 \mu \mathrm{g} / \mathrm{dl})$ & 39 (15.4\%) & $5(3.4 \%)$ & 0.0015 \\
\hline
\end{tabular}

TIBC Total iron binding capacity, TfS Transferrin saturation, HGB hemoglobin, WBC White blood cells, HCT Hematocrit, MCHC Mean corpuscular hemoglobin concentration, MCV Mean corpuscular volume, RDW Red cell distribution width. $p<0.05$ was considered statistically significant different

Values are presented as mean \pm standard deviation, ${ }^{a}$ median (interquartile range). ${ }^{b}$ frequency (percentages)

Table 2 Association between anemia and malaria infection, intestinal parasite and Schistosomiasis among pregnant women

\begin{tabular}{|c|c|c|c|c|}
\hline & Anemic $(n=253)$ & Non-anemic $(n=147)$ & Statistics & $p$-value \\
\hline \multicolumn{3}{|l|}{ Characteristics } & \multicolumn{2}{|l|}{$X^{2}$ value, $d f$} \\
\hline Plasmodium falciparum & & & $6.455,1$ & 0.0111 \\
\hline Not seen & $186(73.5 \%)$ & $132(89.8 \%)$ & & \\
\hline $1+$ & $52(20.6 \%)$ & $14(9.5 \%)$ & & \\
\hline $2++$ & $10(4.0 \%)$ & $1(0.7 \%)$ & & \\
\hline Parasite density(pa/ul)\# & 2159 (926.2-7205.3) & 809.4 (479.3-941.5) & & 0.0487 \\
\hline Intestinal parasite & & & $8.371,2$ & 0.0152 \\
\hline Not seen & $183(72.3 \%)$ & $120(81.6 \%)$ & & \\
\hline $1+$ & $70(27.7 \%)$ & $27(18.4 \%)$ & & \\
\hline Schistosomiasis & & & - & - \\
\hline Not seen & $251(99.2)$ & $147(100.0 \%)$ & & \\
\hline S. haematobium $(++)$ & $1(0.4 \%)$ & - & & \\
\hline S. mansoni $(++)$ & $1(0.4 \%)$ & - & & \\
\hline
\end{tabular}


of $0.4 \%(1 / 253)$ each of S. hematobium $(1+)$ and S. mansoni $(1+)$ infection.

Also, from Table 3, the proportions of AA and CC genotypes between the anemic and non-anemic pregnant women were not statistically significantly different $(p>0.05)$. A significantly higher percentage of the non-anemic (21.8\%) had AC genotype, compared to the anemic $(9.4 \%)(p=0.0327)$. On the other hand, a significantly higher percentage of AS genotype was found among the anemic (16.2\%), compared to non-anemic (4.1\%) pregnant women $(p=0.0081)$. Additionally, SC $4.7 \%(12 / 253)$ and SS genotypes $0.4 \%(1 / 253)$ were found in only the anemic pregnant women.

Subjects who had anemia had a more positive response to C-reactive protein $52.2 \%$ (48/92) than the non-anemic pregnant women $28.8 \%$ (19/66) (Fig. 1).

\section{Discussion}

This study determined the hematological and biochemical changes, along with the occurrence of sickle cell and parasitic infections among anemic and non-anemic pregnant women.

In this study, hematological indices such as $\mathrm{Hb}, \mathrm{HCT}$, $\mathrm{MCHC}$ and MCV levels were lower in anemic pregnant women, compared to their non-anemic counterparts. This is consistent with several studies [24-26] among anemic pregnant women. The mean $\mathrm{Hb}$ level of $9.31 \mathrm{~g} / \mathrm{dl}$ observed among the anemic pregnant women fell within the moderate anemia $(7.0<\mathrm{Hb}<9.9 \mathrm{~g} / \mathrm{dl})$ category, as per WHO classification criteria for anemia [20]. The reduced $\mathrm{HCT}$ can be attributed to the reduced $\mathrm{Hb}$ concentration [27]. Additionally, a reduced HCT may arise from increase in plasma volume and hormonal changes during pregnancy, which cause hemodilution and fluid retention [28].

This study also observed a significantly low mean MCV level among anemic pregnant women, as $16.9 \%$ of them had $\mathrm{MCV}<80 \mathrm{fL}$. A reduced MCV below the lower reference limit, suggests microcytic anemia or iron deficiency anemia [25]. Our finding that MCV levels were reduced in anemic pregnant women is consistent

Table 3 Hemoglobin genotypes of the pregnant women with and without anemia

\begin{tabular}{llll}
\hline Hb Genotype & $\begin{array}{l}\text { Anemic } \\
n=253\end{array}$ & $\begin{array}{l}\text { Non-Anemic } \\
n=147\end{array}$ & $p$-value \\
\hline AA & $166(65.6 \%)$ & $105(71.4 \%)$ & 0.5428 \\
AC & $24(9.5 \%)$ & $32(21.8 \%)$ & 0.0327 \\
AS & $41(16.2 \%)$ & $6(4.1 \%)$ & 0.0081 \\
CC & $9(3.6 \%)$ & $4(2.7 \%)$ & 0.4448 \\
SC & $12(4.7 \%)$ & - & - \\
SS & $1(0.4 \%)$ & - & - \\
\hline
\end{tabular}

Values are presented as $n$ (\%). Comparisons between proportions of anemic and non-anemic groups were performed using Fischer's exact test. $p<0.05$ was considered statistically significant different

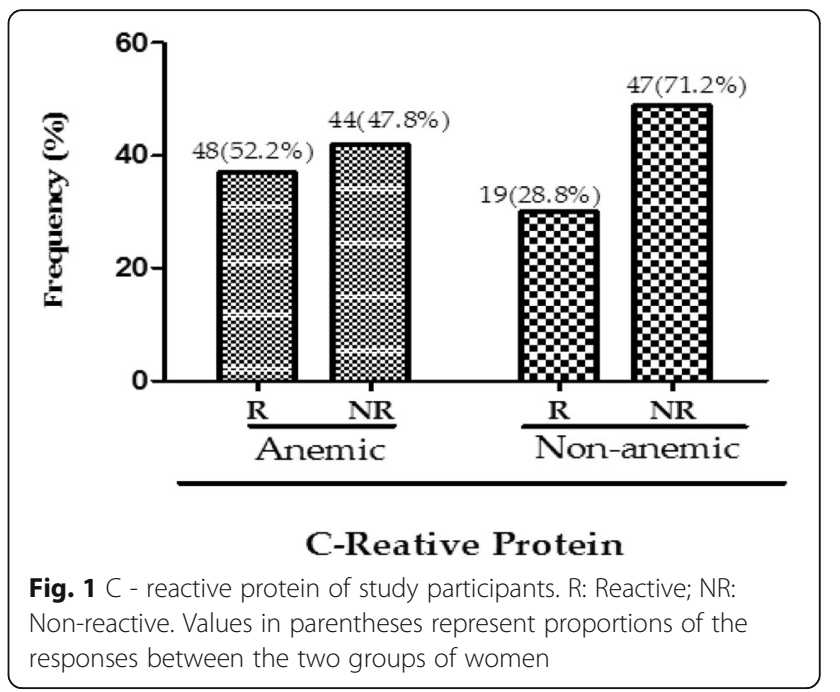

with that of Erhabor et al. who had a similar study [29] among anemic pregnant women in Sokoto, Nigeria. Erhabor and colleagues linked their findings to microcytic hypochromic anemia. The low MCV in our study is further supported by a significant rise in RDW level in the anemic pregnant women, which was above the cut-off point of $15 \%$. The significantly higher proportion of anemic pregnant women who had RDW > 15\% is consistent with the observation made by Tasneem et al. [13].

The significantly lower serum iron, ferritin and transferrin saturation among anemic pregnant women supports the finding by Nuzhat et al. [30]. Low levels of iron, ferritin and transferrin are suggestive of iron deficiency anemia. Our study observed that the proportion of anemic pregnant women with low iron $(<40 \mu \mathrm{g} / \mathrm{dl})$ and ferritin $(<12 \mathrm{ng} / \mathrm{ml})$, were significantly higher among anemic pregnant women; this is another evidence of iron deficiency anemia [15]. We also observed a significantly higher TIBC in the anemic pregnant women. A higher than normal TIBC is an indication of iron-deficiency anemia. Our result corroborates that of Bleyere et al. [31], in a study among pregnant women in Cote d'lvoire. The probable explanation to the high TIBC levels among anemic pregnant women could be the reduced iron and \% transferrin saturation [32].

The present study shows non-significantly lower levels of bilirubin among anemic pregnant women. The low bilirubin levels among the anemic pregnant women probably rules out hemolysis of the red cells.

Increased WBC could be as a result of increased inflammation and/or defensive immune response to infection [33]. This study observed a non-significantly increased levels of total WBC count among anemic pregnant women, compared to non-anemic women. Luppi [34] observed an increasing level of total lymphocyte count 
throughout pregnancy, which could be due to maternal body's attempt to build up immunity. Our present study observed that majority of anemic pregnant women had parasitic infections like malaria and schistosomiasis; hence the elevated WBC is more likely to be attributed to these infections [33]. Although the mean WBC of anemic pregnant women in this study was elevated, it was within the reference range.

In the present study, the positive response of anemic pregnant women to C-reactive protein was $52.2 \%$ while non-anemic pregnant women showed $28.8 \%$. A study by Mburu et al. [35] indicated that C-reactive protein levels $>6 \mathrm{ng} / \mathrm{ml}$ is indicative of increased inflammatory response, due to parasitic infections and or hemoglobinopathies.

From this study, Hb genotypes AS, SC and SS may have contributed to the higher number of anemic pregnant women due to the increased proportion of sickle cell trait and disease in the participants. Anemia is a major feature of sickle cell disease due to defective haemoglobin structure [36]. Anemia in pregnancy complicated by sickle cell disease or trait had been reported by Desai et al. [37]

In our previous study, an increased proportion of Plasmodium falciparum malaria and intestinal helminthes infections were observed among anemic pregnant women, compared to non-anemic pregnant women. Our current study supports our previous study [21] that anemic pregnant women reported with an increased proportion of Plasmodium falciparum, Schistosoma hematobium and intestinal parasites. This confirms the explanation that malaria and intestinal parasite infections coexist with micronutrient deficiencies, culminating in anemia [38].

The main strength of this study is the fact that despite working from a less resourced setting, we have been able to combine the measurement of biochemical and hematological parameters, unlike many other studies, where the two types of tests had been done independently. These measurements were done concurrently on same subjects, whereas in other studies, different subjects were used.

Despite these strengths, there were some limitations of our study. The use of single slide for parasite detection, cross-sectional nature of the study, inability to analyse all samples for CRP and the general lack of reference intervals specific to the local condition in Bolgatanga, which necessitated the comparison of the results of this study with data from countries whose socio-demographic variables vary from our local setting. Other micronutrients such as vitamin A, folate, cyanocobalamin, and zinc were not assessed in this study. Their influence on the burden of anemia in this setting can therefore become a subject for further scientific investigation.

\section{Conclusion}

Anemic pregnant women are associated with some changes in hematological and iron indices including significantly reduced $\mathrm{Hb}, \mathrm{HCT}, \mathrm{MCV}$, iron, ferritin and transferrin saturation and increased WBC, RDW, TIBC and positivity of CRP. These changes could have been influenced by a higher proportion of hemoglobinopathies, Plasmodium falciparum, Schistosoma hematobium and intestinal parasite.

\section{Abbreviations \\ CHRPE-KNUST/KATH: Committee on Human Research, Publication and Ethics of Kwame Nkrumah University of Science and Technology and Komfo Anokye Teaching Hospital; CRP: C-reactive protein; \\ EDTA: Ethylenediaminetetraacetic acid; HCT: Hematocrit; HGB/ Hb: Hemoglobin; IRB-NHRC: Institutional Review Board of the Navrongo Health Research Centre; MCH: Mean Corpuscular Hemoglobin; MCHC: Mean Corpuscular Hemoglobin Concentration; MCV: Mean Corpuscular Volume; MEIA: Microparticle Enzyme Immunoassay; PCV: Packed Cell Volume; RBC: Red Blood Cell; RDW: Red Cell Distribution Width; RHB-ANC: Regional Hospital Bolgatanga Antenatal Clinic; SST: Serum Separator Tube; TfS: Transferrin Saturation; TIBC: Total Iron Binding Capacity; UIBC: Unbound Iron Binding Capacity; WBC: White Blood Cell}

\section{Acknowledgements}

We are grateful to the Committee on Human Research, Publication and Ethics of Kwame Nkrumah University of Science and Technology and Komfo Anokye Teaching Hospital (CHRPE-KNUST/KATH) and the Institutional Review Board of the Navrongo Health Research Centre (IRB-NHRC), for approving this study. The authors of this paper are also grateful to all the participating women, the midwives and administrative staff of Bolgatanga Regional Hospital. Our special thanks go to all staff of the Bolgatanga Regional Hospital Laboratory department for their immense technical support in the assay of our specimens.

\section{Funding}

This was self-funded by the corresponding author.

\section{Availability of data and materials}

The datasets used and analysed during the current study are available from the corresponding author on reasonable request.

\section{Authors' contributions}

$\mathrm{BA}, \mathrm{KN}$ and $\mathrm{PB}$ designed the study and $\mathrm{BA}$ carried out the clinical and laboratory work, BA and $\mathrm{KN}$ drafted the paper and $\mathrm{KN}$ revised the paper. $B A$ provided reagents and consumables for the study. EOA interpreted and analysed the data. All authors read and approved the final manuscript and they are guarantors of the paper.

\section{Ethics approval and consent to participate}

The ethical approval of the research protocol was granted by two review boards. Firstly, the Committee on Human Research, Publication and Ethics of Kwame Nkrumah University of Science and Technology and Komfo Anokye Teaching Hospital (CHRPE-KNUST/KATH) reviewed and approved it and secondly, it was reviewed and approved by the Institutional Review Board of the Navrongo Health Research Centre (IRB-NHRC). Pregnant women attending their first antenatal visit at the RHB-ANC were approached and the rationale of the study was explained to them. Written informed consent was then obtained from all participants and guardians of participants who were younger than 16 years. In the process of seeking informed consent, the aims and objectives of the study, as well as the benefits of the proposed study, were explained to the participants.

Consent for publication

Not applicable.

Competing interests

The authors declare that they have no competing interests. 


\section{Publisher's Note}

Springer Nature remains neutral with regard to jurisdictional claims in published maps and institutional affiliations.

\section{Author details \\ 'Biochemistry and Hematology Units, Bolgatanga Regional Hospital, P.O. Box 26, Bolgatanga-Upper East Region, Ghana. ${ }^{2}$ Department of Biochemistry and Biotechnology, Kwame Nkrumah University of Science and Technology, Kumasi, Ghana. ${ }^{3}$ Obstetrics and Gynecology Unit, Bolgatanga Regional Hospital, P.O. Box 26, Bolgatanga-Upper East Region, Ghana. ${ }^{4}$ Department of Biochemistry and Molecular Medicine, School of Medical and Health Science, University for Development Studies, Tamale, Ghana. ${ }^{5}$ Department of Molecular Medicine, School of Medical Science, Kwame Nkrumah University of Science and Technology, Kumasi, Ghana. ${ }^{6}$ Department of Medical Laboratory Technology, Royal Ann College of Health, Atwima-Manhyia, Kumasi, Ghana. ${ }^{7}$ School of Medical and Health Science, Edith Cowan University, Perth, WA, Australia.}

\section{Received: 9 March 2017 Accepted: 3 September 2018}

\section{Published online: 17 September 2018}

\section{References}

1. Nguyen V, Wuebbolt D, Thomas H, Murphy K, D'souza R. Iron deficiency Anemia in pregnancy and treatment options: a patient-preference study [1L]. Obstet Gynecol. 2017;129:122S

2. Balarajan $Y$, Ramakrishnan U, Özaltin E, Shankar AH, Subramanian S. Anaemia in low-income and middle-income countries. Lancet. 2011; 378(9809):2123-35.

3. Mwangi MN, Prentice AM, Verhoef $\mathrm{H}$. Safety and benefits of antenatal oral iron supplementation in low-income countries: a review. Br J Haematol. 2017;177(6):884-95.

4. Tay SCK, Nani EA, Walana W. Parasitic infections and maternal anaemia among expectant mothers in the Dangme East District of Ghana. BMC Res Notes. 2017;10(1):3.

5. Gernand AD, Aguree S, Pobee R, Murray-Kolb LE. Micronutrient deficiencies in Ghanaian women before pregnancy. FASEB J. 2017;31(1 Supplement) 786.720-786.720

6. Anlaakuu P, Anto F. Anaemia in pregnancy and associated factors: a cross sectional study of antenatal attendants at the Sunyani municipal hospital, Ghana. BMC Res Notes. 2017;10(1):402.

7. Otto JM, Plumb JO, Clissold E, Kumar S, Wakeham DJ, Schmidt W, Grocott MP, Richards T, Montgomery H. Hemoglobin concentration, total hemoglobin mass and plasma volume in patients: implications for anemia. Haematologica. 2017; 2017.169680

8. Arimond M, Vitta BS, Martin-Prével Y, Moursi M, Dewey KG. Local foods can meet micronutrient needs for women in urban Burkina Faso, but only if rarely consumed micronutrient-dense foods are included in daily diets: a linear programming exercise. Matern Child Nutr. 2017;

9. Percy L, Mansour D, Fraser I. Iron deficiency and iron deficiency anaemia in women. Best Prac Res Clin Obstet Gynaecol. 2017:40:55-67.

10. Orlandini C, Torricelli M, Spirito N, Alaimo L, Di Tommaso M, Severi FM, Ragusa A, Petraglia F: Maternal anemia effects during pregnancy on male and female fetuses: are there any differences? J Matern Fetal Neonatal Med 2017, 30(14):1704-1708.

11. Yildiz Y, Özgü E, Unlu SB, Salman B, Eyi EGY. The relationship between third trimester maternal hemoglobin and birth weight/length; results from the tertiary center in Turkey. J Matern Fetal Neonatal Med. 2014;27(7):729-32.

12. Darnton-Hill I, Mkparu UC. Micronutrients in pregnancy in low-and middleincome countries. Nutrients. 2015;7(3):1744-68.

13. Tasneem S, Sultana N, Snover A, Alam K. Clinical utility of red blood cell count, red cell distribution width: will it provide more accurate differentiation of Beta thalassemia trait and iron deficiency anemia in pregnancy? Rawal Med J. 2016;41(4):424-7.

14. Rayis DA, Ahmed MA, Abdel-Moneim H, Adam I, Lutfi MF. Trimester pattern of change and reference ranges of hematological profile among Sudanese women with normal pregnancy. Clin Prac. 2017;7(1):888.

15. Lopez A, Cacoub P, Macdougall IC, Peyrin-Biroulet L. Iron deficiency anaemia. Lancet. 2016:387(10021):907-16.

16. World Health Organization. Iron deficiency anaemia: assessment, prevention, and control. In: A guide for programme managers. Geneva: WHO; 2001. NHD Publicação 2015(01.3).
17. Daru J, Allotey J, Peña-Rosas JP, Khan KS. Serum ferritin thresholds for the diagnosis of iron deficiency in pregnancy: a systematic review. Transfus Med. 2017;27(3):167-74.

18. Abdelgader EA, Diab TA, Kordofani AA, Abdalla SE. Haemoglobnin level, RBCs indices, and iron status in pregnant females in Sudan. Basic Res J Med Clin Sci. 2014;3(2):8-13.

19. Tunkyi K, Moodley J. Anemia and pregnancy outcomes: a longitudinal study. J Matern Fetal Neonatal Med. 2017:1-5.

20. World Health Organization: Worldwide prevalence of anaemia 1993-2005: WHO global database on anaemia 2008.

21. Ahenkorah B, Nsiah K, Baffoe P. Sociodemographic and obstetric characteristics of Anaemic pregnant women attending antenatal clinic in Bolgatanga regional hospital. Scientifica. 2016;2016:1-8.

22. Haggaz AD, Elbashir LM, Adam GK, Rayis DA, Adam I. Estimating malaria parasite density among pregnant women at Central Sudan using actual and assumed white blood cell count. Malar J. 2014;13(1):6.

23. WHO. Basic Malaria Microscopy - Part I: Learner's guide. Second edition www.who.int/malaria/publications/atoz/9241547820/en/; 2010.

24. Karaoglu L, Pehlivan E, Egri M, Deprem C, Gunes G, Genc MF, Temel I. The prevalence of nutritional anemia in pregnancy in an east Anatolian province, Turkey. BMC Public Health. 2010;10(1):329.

25. Getahun W, Belachew T, Wolide AD. Burden and associated factors of anemia among pregnant women attending antenatal care in southern Ethiopia: cross sectional study. BMC Res Notes. 2017;10(1):276.

26. Susanti Al, Sahiratmadja E, Winarno G, Sugianli AK, Susanto H, Panigoro R. Low hemoglobin among pregnant women in midwives practice of primary health care, Jatinangor, Indonesia: Iron deficiency Anemia or $\beta$-thalassemia trait? Anemia. 2017:5. Article ID 6935648.

27. James TR, Reid HL, Mullings AM. Are published standards for haematological indices in pregnancy applicable across populations: an evaluation in healthy pregnant Jamaican women. BMC pregnancy and childbirth. 2008;8(1):8.

28. Stevens GA, Finucane MM, De-Regil LM, Paciorek CJ, Flaxman SR, Branca F, Peña-Rosas JP, Bhutta ZA, Ezzati M, Group NIMS. Global, regional, and national trends in haemoglobin concentration and prevalence of total and severe anaemia in children and pregnant and non-pregnant women for 1995-2011: a systematic analysis of population-representative data. Lancet Glob Health. 2013;1(1):e16-25.

29. Erhabor O, Isaac I, Isah A, Udomah F. Iron deficiency anaemia among antenatal women in Sokoto, Nigeria. Br J Med Health Sci. 2013;1(4):47-57.

30. Raza N, Sarwar I, Munazza B, Ayub M, Suleman M. Assessment of iron deficiency in pregnant women by determining iron status. J Ayub Med Coll Abbottabad. 2011;23(2):36-40.

31. Bleyere MN, Bi ASN, Kone M, Sawadogo D, Yapo PA: Iron status and red cell parameters in pregnant and non-pregnant adolescents in Côte d'Ivoire (West Africa). 2014

32. Villers M, Grimsley A, James A, Heine RP, Cooper A, Swamy G. 512: collaboration of care improves outcomes among pregnant women with iron deficiency anemia. American Journal of Obstetrics \& Gynecology. 2016; 214(1):\$278

33. Adikwu P, Amuta E, Obande G, Adulugba A, Abba E. Studies on malaria parasite and Haemoglobin level among pregnant women attending antenatal at Benue state general hospital, Otukpo, Nigeria. Am J Med Med Sci. 2017;7(6):265-70.

34. Luppi P. How immune mechanisms are affected by pregnancy. Vaccine. 2003;21(24):3352-7.

35. Mburu AS, Thurnham DI, Mwaniki DL, Muniu EM, Alumasa F, De Wagt A: The influence and benefits of controlling for inflammation on plasma ferritin and hemoglobin responses following a multi-micronutrient supplement in apparently healthy, HIV+ Kenyan adults. J Nutr 2008, 138(3):613-619.

36. Yu C, Stasiowska E, Stephens A, Awogbade M, Davies A. Outcome of pregnancy in sickle cell disease patients attending a combined obstetric and haematology clinic. J Obstet Gynaecol. 2009;29(6):512-6.

37. Desai G, Anand A, Shah P, Shah S, Dave K, Bhatt H, Desai S, Modi D. Sickle cell disease and pregnancy outcomes: a study of the community-based hospital in a tribal block of Gujarat, India. J Health Popul Nutr. 2017:36(1):3

38. Anchang-Kimbi JK, Elad DM, Sotoing GT, Achidi EA. Coinfection with Schistosoma haematobium and Plasmodium falciparum and Anaemia severity among pregnant women in Munyenge, Mount Cameroon area: A cross-sectional study. J Parasitol Res. 2017:12. Article ID 6173465. 